\title{
Effect of acute lead intoxication on behavior in adult and young wistar rats Missoun Fatiha*1 and Slimani Miloud ${ }^{2}$
}

Address: ${ }^{1}$ Departement of biotechnology, Faculty of Sciences, University of Mostaganem 27000, Algeria and ${ }^{2}$ Departement of Biology, Faculty of Sciences, University of Oran 31000, Algeria

* Corresponding author

from International Society on Brain and Behaviour: 3rd International Congress on Brain and Behaviour

Thessaloniki, Greece. 28 November - 2 December 2007

Published: 17 April 2008

Annals of General Psychiatry 2008, 7(Suppl I):S292 doi:I0.II86/I744-859X-7-SI-S292

This abstract is available from: http://www.annals-general-psychiatry.com/content/7/SI/S292

(c) 2008 Fatiha and Miloud; licensee BioMed Central Ltd.

\section{Background}

Lead has been shown to produce cognitive and motor deficits in young rats that could be mediated, In the present study we investigated the effects of lead treatment during the first stage and the aging stage.

\section{Materials and methods}

For this purpose, young and adult rats were injected daily for one week with lead acetate at a dose of $15 \mathrm{mg} / \mathrm{kg}$ body weight.

\section{Results}

Administration of lead acetate to young rats for one week caused a reduction in locomotor activity and stereotypic exploratory behavior during a $20 \mathrm{~min}$ testing period. This locomotor hypoactivity induced by lead was accompanied by a reduction in stereotypic behaviour compared to adults and control groups These outcomes

\section{Conclusions}

The results of the present study suggest that $\mathrm{Pb}$ can be a potential risk factor for metabolic accelerator in the cognition impairment and some neurodegenerative disorders. 